\title{
CALIGRAFIAS E ESCRITURAS: DIÁLOGO E INTERTEXTO NO PROCESSO ESCRITURAL NAS ARTES NO SÉCULO $X X$
}

Maria do Carmo de Freitas Veneroso*

RESUMO:

Este é um estudo a respeito do diálogo e das relações intertextuais no processo escritural nas artes do século XX. Nele, são discutidas as relações entre imagem e texto em alguns momentos do modernismo e pós-modernismo, abarcando também a arte brasileira recente.

PALAVRAS-CHAVE: écriture, intertexto, imagem e texto.

Caligrafias e Escrituras tem como ponto de partida o estudo do texto visual nas artes plásticas no século XX e sua relação intertextual interna e externa com a literatura, na busca de novos parâmetros para essas relações.

Ao mesmo tempo em que artistas plásticos enfatizam a visualidade e a materialidade da escrita em seus trabalhos, também os poetas têm se encaminhado na direção de uma conscientização da página como parte constituinte do poema e na exploração da visualidade e da materialidade da escrita. Há, no século XX, uma reintegração das palavras no discurso plástico, quando elas irrompem no espaço do quadro ao mesmo tempo em que a visualidade dos signos lingüísticos e do espaço da página é resgatada pelos poetas.

Essa aparição da letra no espaço do quadro e a exploração da visualidade da letra na poesia está ligada a vários fatores. A dissolução dos limites precisos entre as linguagens artísticas e o diálogo cada vez maior entre as categorias artísticas pode ser apontada como uma das possíveis explicações para isso. A desconstrução da escrita tem feito com que escrita e desenho se encontrem num lugar limítrofe que é um local privilegiado para se pensar as relações entre imagem e palavra.

* Doutora em Letras: Estudos Literários (Área de concentração: Literatura Comparada), 2000. 


\section{EM TESE}

Belo Horizonte, v. 5, p. I-305, dez. 2002

Também o movimento pendular na arte tem levado os artistas e poetas a buscar a visualidade da letra, reafirmando a origem visual da escrita. Esse diálogo que a arte do século XX estabelece com a escrita, ao mesmo tempo em que a escrita dialoga com a visualidade da letra, reata, de certa maneira, antigos vínculos existentes entre a palavra e a imagem, entre o traço do desenho e o traço da escrita, revelando que a escrita não é apenas um meio de transcrição da fala, mas é uma realidade dupla, dotada de uma parte visual.

Para estudar a questão do diálogo entre as artes, os conceitos de écriture (Barthes) e intertextualidade (Bakhtine/Kristeva/Compagnon) compõem 0 quadro teórico. A aplicação do conceito de écriture, de Roland Barthes, às artes plásticas, leva a pensá-la não como uma função da linguagem, mas como uma desfuncionalização, pois explora não as "riquezas infinitas" de um texto, mas seus pontos de resistência, forçando-o a significar o que está além de suas funções. É essa significação do texto "além de suas funções", que leva a admitir o uso de écriture nas artes plásticas.

Considerando as artes plásticas como um sistema de significação, que tem signos tal qual a escrita, podemos ler a arte do século XX, principalmente a arte mais recente, como um processo intertextual de reescrita de outros textos. A intertextualidade designa o trabalho de transformação e assimilação de vários textos, operado por um texto centralizador, que irradia sentidos. A produção do outro "texto" se dá através de procesos de rapto, absorção e integração de elementos alheios na criação da obra nova. Essa relação não se dá como uma relação de mera influência, mas de diálogo. Assim os artistas criam seus precursores, sendo que seu trabalho modifica nossa concepção do passado, como há de modificar o futuro (Borges, 1981:109).

Como afirma Anne-Marie Christin (1995:5) a escrita nasceu da imagem, considerando o termo escrita no seu senso estrito de veículo gráfico de uma fala. Assim sendo, a arte do século XX pode ser vista como uma tentativa de reatar os antigos vínculos existentes entre escrita e imagem, tendo como precursores Mallarmé, com Un Coup de Dés e Picasso e Braque, com os papier-collés. Ao mesmo tempo em que poetas como Mallarmé restauram a visualidade do poema, artistas plásticos vão buscar no texto a sua visualidade, a sua materialidade. Há um lugar fronteiriço, 
onde imagem e texto se encontram, sendo que, ao mesmo tempo em que a escrita explora a sua visualidade, a arte restitui à escrita sua materialidade, sua qualidade de "coisa desenhada".

Mallarmé desconstrói o texto no poema Un Coup de Dés (Fig.1) e esse processo pode ser comparado à desconstrução da escrita realizada pelos artistas contemporâneos. Barthes aproxima o procedimento do pintor Cy Twombly (Fig.2) ao de Mallarmé, dizendo que Mallarmé quis desconstruir a frase, assim como Twombly desconstrói a escritura. (Barthes, 1990:146).

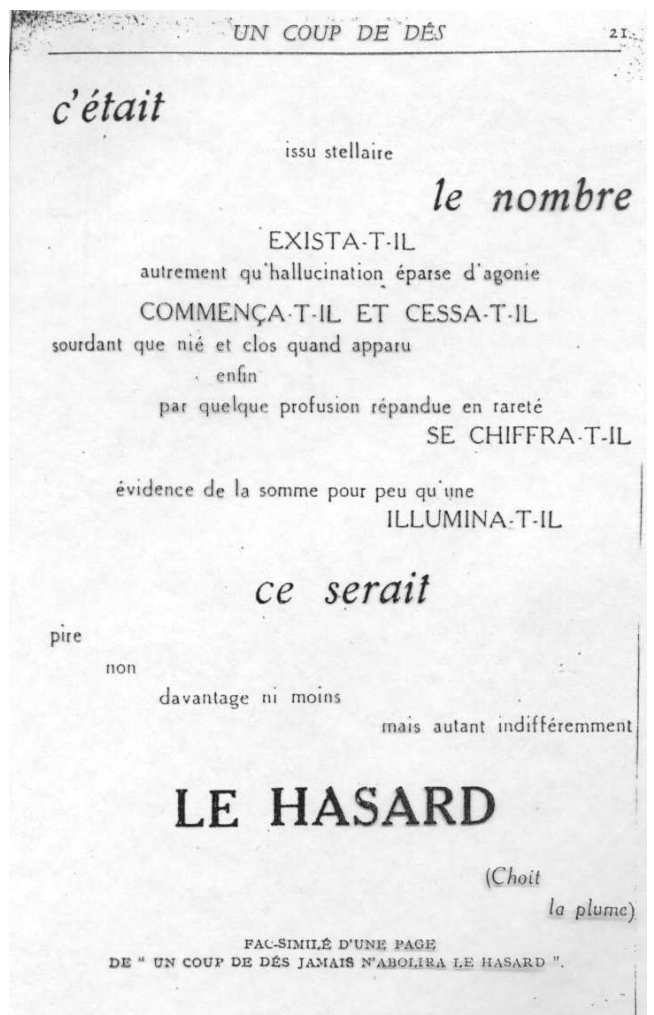

Figura 1 - Stéphane Mallarmé. Un coup de dés jamais n'abolira le hasard. Poema.

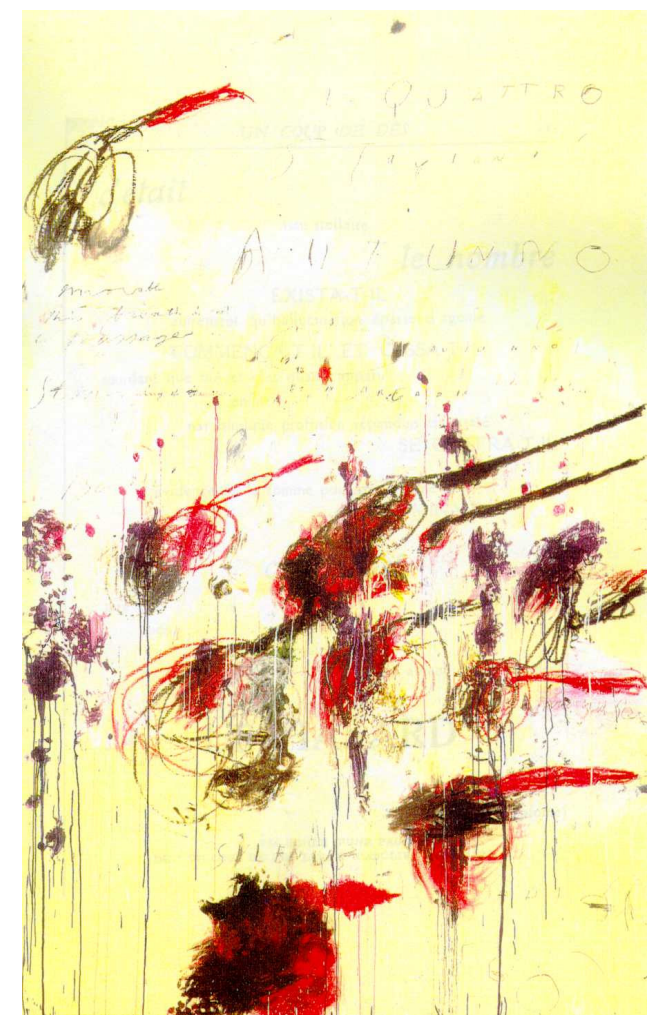

Figura 2 - Cy Twombly. As quatro estações: Outono. Tinta acrílica, óleo, lápis e crayon sobre tela.

A exploração de recursos gráficos junto ao texto, realizada por Mallarmé, com Un Coup de Dés, teve vários desdobramentos, entre eles, o trabalho de Apollinaire, com seus Calligrammes e também as experiências futuristas de neotipografia, como Les mots en liberté, de Marinetti e L'antitradition futuriste, de Apollinaire, vindo a se cristalizar mais tarde nas obras de Joyce, Pound e cummings. Explorando ainda os recursos gráficos junto ao texto, podemos citar os experimentos dos 


\section{EM TESE}

Belo Horizonte, v. 5, p. I-305, dez. 2002

dadaístas, como por exemplo o manifesto de Tristan Tzara, DADA souleve tout e vários poetas, entre eles Giuseppe Ungaretti, com seu poema Perfections du noir e ainda a poesia concreta.

Paralelamente a esse movimento em direção a uma poesia que utiliza, cada vez mais, elementos plásticos, ocorria uma situação análoga nas artes plásticas, com os artistas utilizando, cada vez mais, recursos da escrita em seus trabalhos. Podemos dizer que a palavra apareceu pela primeira vez no espaço do quadro, de uma maneira mais sistemática e integrada ao discurso plástico, na produção dos pintores cubistas, na década de 1910, ao mesmo tempo em que Apollinaire (Fig.3) realizava trabalho semelhante com seus caligramas, nos quais, tal como Picasso (Fig.4), ele também discute as relações espaço/tempo, e nos quais a letra é imagem e a imagem é letra.

Vários foram os artistas que seguiram o caminho aberto por Picasso com suas colagens. Entre eles, se encontra Kurt Schwitters, que explorou profundamente

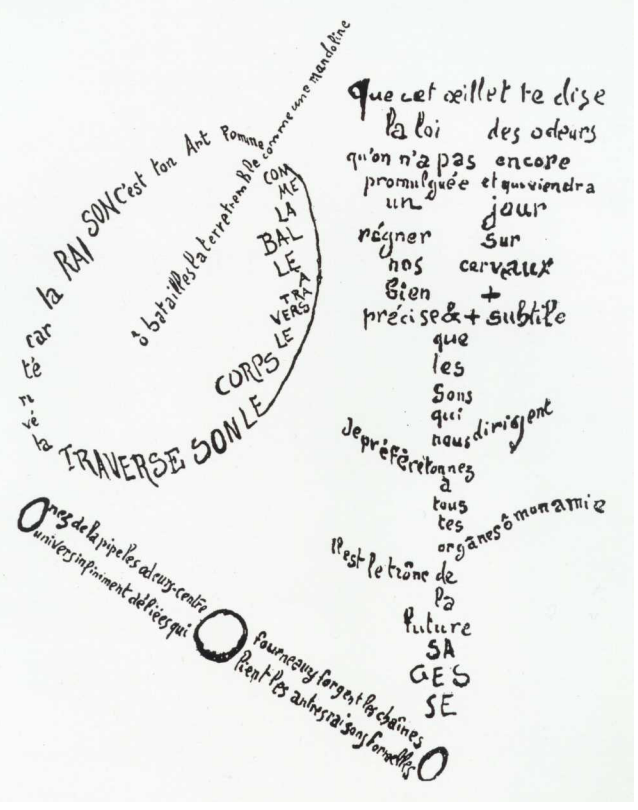

Figura 3 - Guillaume Apollinaire. O bandolim, a violeta e o bambu. Caligrama.

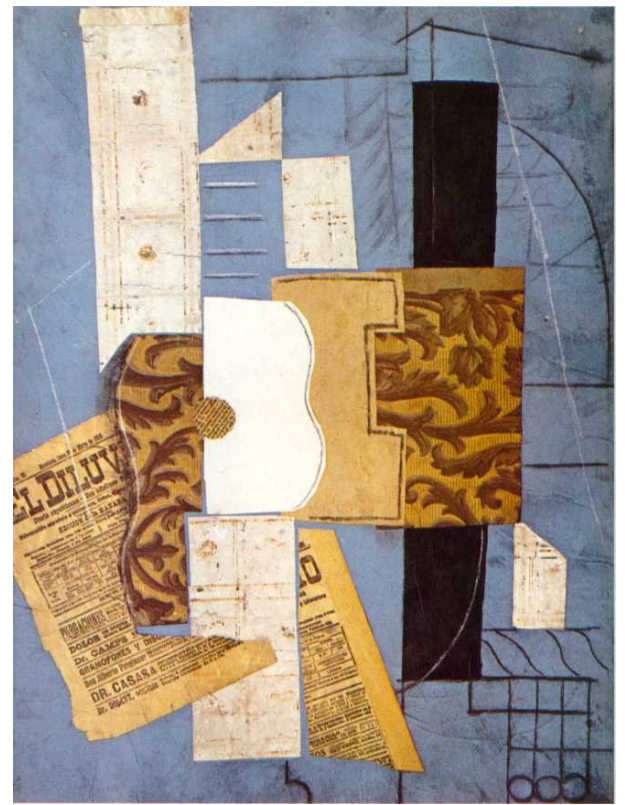

Figura 4 - Pablo Picasso. Guitar. Carvão, crayon, tinta e colagem.

as possibilidades da incorporação de materiais não "artísticos" em seus trabalhos, dando ênfase à natureza dos materiais e suas relações. Com suas colagens verbais e colagens visuais, ele trabalha a questão integrativa da linguagem, contribuindo, dessa forma, para a destruição dos limites rígidos entre as diferentes linguagens. 
Marcel Duchamp estabelece relações entre a linguagem verbal e a linguagem plástica em seus trabalhos. Com o ready made, ele destrói a noção de obra, com o jogo de palavras, ele destrói o significado.

Paul Klee, ao incorporar signos gráficos em seus quadros, abole a existência de uma hierarquia entre imagem e escrita. Através de um trabalho intertextual, no qual ele incorpora signos, letras e ideogramas, ele reafirma a visualidade da escrita, extinguindo o princípio ocidental que estabelece a diferença entre representação plástica e referência lingüistica.

Robert Motherwell cria um trabalho intertextual com a escrita ideogramática. A escritura na obra de Motherwel1 não é um instrumento de comunicação, aproximando-se do conceito de écriture de Barthes, já que seus gestos são uma fusão de pensamento e impulso inconscientes.

0 trabalho de Robert Rauschenberg intertextualiza com a cultura de massas. 0 artista trabalha com fragmentos, que ele extrai, mutila, desenraíza. Seu trabalho se aproxima da música, da dança e da poesia beat, já que eles tiveram em comum em romper os limites entre arte e vida.

Jean-Michel Basquiat se apropria do graffiti de rua, levando-o para a galeria. Em Basquiat, a letra é escrita e é desenho. Desenho infantil, desenho primitivo, desenho de quem escreve o desenho.

Com Kiefer, a tendência textual na arte do século XX alcança o ápice, através de sua apropriação do livro, veículo, ícone principal da palavra escrita.

Com Ann Hamilton, a tendência conceitual na arte do século XX alcança uma nova dimensão, na maneira pela qual essa artista trabalha o conceito de instalação, introduzindo um importante elemento que é a fala. Na instalação tropos (Figs.5 e 6) palavras são canceladas, tornadas difíceis: a palavra escrita, por meio da queima e a palavra falada através da fala de um indivíduo afásico.

$\mathrm{Na}$ arte brasileira recente, também tem ocorrido a apropriação da língua por parte de vários artistas, entre eles, Lotus Lobo. Essa artista realiza um trabalho de devoração antropofágica, através da apropriação de antigos rótulos da estamparia litográfica, com os quais ela gera imagens poéticas, discutindo a própria linguagem gráfica, em um processo de devoração e releitura. 


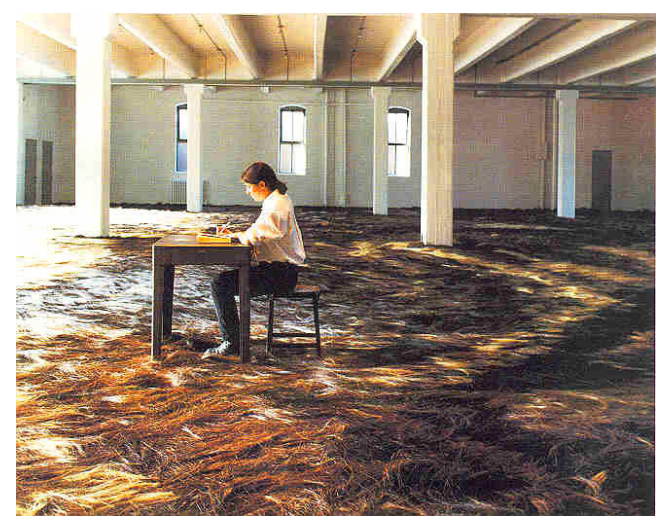

Figura 5 - Ann Hamilton. tropos. Instalação no Dia Art Foundation, New York.

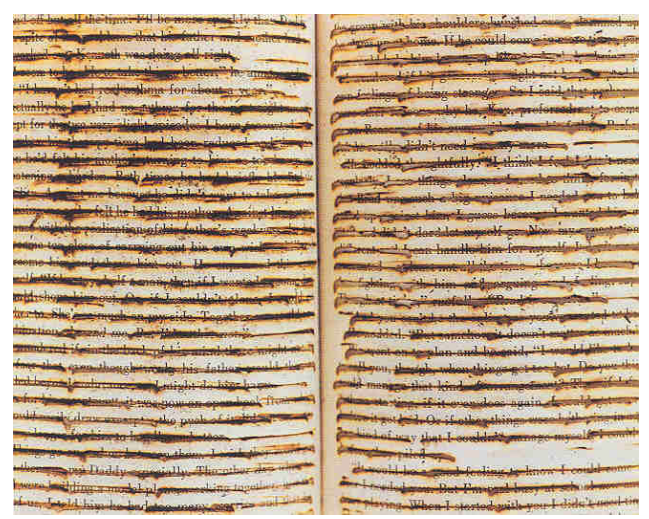

Figura 6 - Ann Hamilton. tropos. Instalação (detalhe).

Arlindo Daibert trabalha a relação entre imagem e texto nos terrenos onde esse embate se dá: no livro e no quadro. Esse artista trabalha com textos visuais, explorando a visualidade da letra e as relações entre arte e literatura, onde a "citação" literária é a fonte de criação de suas poéticas visuais.

Tanto o trabalho de Leonilson quanto o de Arthur Bispo do Rosário são textos de fronteira: o limite entre a saúde e a doença, no primeiro e entre a lucidez e o delírio, no segundo.

Assim, nota-se que a presença de um grande número de artistas desconstruindo textos e criando intertextos escriturais no decorrer do século XX é constante. Tendo encontrado condições propícias para seu desenvolvimento, essa forte tendência da contemporaneidade se radicalizou no trabalho de alguns e surgiu de forma mais sutil no trabalho de outros. A subordinação entre imagem e texto foi quebrada, não existindo mais uma hierarquia entre ambos. Não há mais a preocupação em explicitar uma imagem, como acontece nas legendas ou nos títulos, assim como não se trata de ilustrar um texto ou de um discurso que gira em torno da pintura. As palavras se integram ao discurso plástico, tornadas, elas mesmas, imagens.

Em alguns artistas, a aproximação entre imagem e texto se dá através da apropriação de elementos da escrita no espaço do quadro, como em Braque, Picasso e Schwitters. Já no trabalho de outros artistas, como Klee, Motherwell e Cy Twombly, a escrita remete às garatujas e a diferentes alfabetos. A palavra transgressora surge nos graffiti e nos trabalhos de artistas com Basquiat. 0 restabelecimento das 
relações entre arte e literatura se dá em trabalhos de artistas como Daibert e Kiefer, ao mesmo tempo em que a materialidade da palavra está presente em obras de Ann Hamilton e Barbara Kruger. Também na poesia visual recente nota-se uma ênfase maior na imagem, como em Joan Brossa, apontando, mais uma vez, para a ruptura dos limites entre as categorias artísticas.

A aparição da letra no espaço do quadro e a exploração da visualidade da letra na poesia estão ligadas, portanto, a vários fatores: a dissolução dos limites precisos entre as linguagens artísticas, sendo que as categorias artísticas têm se misturado cada vez mais, com a aproximação entre as artes; a desconstrução das categorias tradicionais tem feito com que escrita e desenho se encontrem; a questão do movimento pendular na arte, que tem levado os artistas a buscar a visualidade da letra, reafirmando a origem visual da escrita.

Palavras, letras, grafismos, caligrafias, escrituras, manuscritos, poemas, graffiti, desenhos, design, o livro: imagem da escrita, escrita da imagem.

ABSTRACT :

This paper aims at studying the dialogue and inter-textual relathioships which operate in the process of écriture within the arts in the 20th Century. Relationships between image and text in some moments of modernism and postmodernism are discussed, also with relation to recent Brazilian art.

KEY WORDS: écriture, inter-text, image and text. 
BARTHES, Roland. O óbvio e o obtuso. Rio de Janeiro: Nova Fronteira, 1990.

- O rumor da língua. Lisboa: Edições 70, 1984. (Coleção Signos).

. S/Z. Rio de Janeiro: Nova Fronteira, 1992.

BERNARDINI, Aurora Fornoni (Org.) o futurismo italiano. Manifestos. São Paulo: Perspectiva, 1980.

BLANCHOT, Maurice. O espaço literário. Rio de Janeiro: Rocco, 1987.

BORGES, J. L. Kafka e sus precursores. In: Otras inquisiciones. Madrid: Alianza Editorial, 1981.

BRETON, Andre. Manifestos do surrealismo. São Paulo: Brasiliense, 1985.

BRITO, Ronaldo. Neoconcretismo - Vértice e Ruptura do Projeto Construtivo Brasileiro. Rio de Janeiro: Funarte, 1985.

BRITT, David. Modern art. impressionism to post-modernism. London: Thames and Hudson, 1989.

BUTOR, M. Les mots dans la peinture. Paris: Skira, 1969. CAMPOS, Augusto de; PIGNATARI, Décio; CAMPOS, Haroldo de. MALlarmÉ. São Paulo: Perspectiva, 1991.

- A arte no horizonte do provável. São Paulo: Perspectiva, 1977.

CHRISTIN, Anne-Marie. L'image écrite. Paris: Flammarion, 1995.

COMPAGNON, Antoine. O trabalho da citação. Belo Horizonte: Editora UFMG, 1996.

COOKE, Lynne, KELLY, Karen (Ed.). Robert Lehman lectures on contemporary art. New York: Dia Center for the Arts, 1996.

COOPER, Martha, CHALFANT, Henry. Subway art. New York: Henry Holt Company, 1995.

CUMmings, e.e. 40 poemas. Trad. Augusto de Campos. São Paulo: Brasiliense, 1985.

DAIBERT, Arlindo. Caderno de escritos. Rio de Janeiro: Sette Letras, 1995.

DERRIDA, Jacques. A escritura e a diferença. São Paulo: Perspectiva, 1995.

DOMINGUES, Diana. A arte do século XXI: a humanização das tecnologias. São Paulo: Editora UNESP, 1997.

DUCHAMP, Marcel. Escritos. Duchamp du signe. Barcelona: Gustavo Gilli, 1978.

ELIOT, T. S. Quatro quartetos. Trad. Ivan Junqueira. Rio de Janeiro: Civilização Brasileira, 1967.

FINEBERG, Jonathan. Art since 1940. Strategies of being. London: Laurence King Publishing, 1995.

FIZ, Simon Marchán. Del arte objetual al arte de concepto. Madrid: Alberto Corazon Editor, 1974.

FOSTER, Hal. Recodificação. São Paulo: Casa Editorial Paulista, 1996. 
FOUCAULT, Michel. Isto não é um cachimbo. Rio de Janeiro: Paz e Terra, 1989.

FRIEDRICH, Hugo. Estrutura da lírica moderna. São Paulo: Duas Cidades, 1991.

GEELHAAR, Chrintian. Paul Klee et le Bauhaus. Neuchâtel: Editions Ides et Calendes, 1972.

HIdALGO, Luciana. Arthur Bispo do Rosário - 0 senhor do labirinto. Rio de Janeiro: Rocco, 1996.

HOLLANDA, Heloisa Buarque (Org.) Pós-modernismo e política. Rio de Janeiro: Rocco, 1992.

HUYSSEN, Andreas. After the great divide: modernism, mass culture, postmodernism. Bloomington and Indianapolis: Indiana University Press, 1987.

KRISTEVA, Julia. La révolution de la langage poétique. Paris: Seuil, 1974.

LAGNADO, Lisette. Leonilson: são tantas as verdades. São Paulo: DBA Melhoramentos, 1998.

MALlarmé, S. Poemas. São Paulo: Perspectiva, 1974.

MARSHALL, Richard (Org.). Jean-Michel Basquiat. New York: Whitney Museum of American Art, 1993.

MENEZES, Philadelpho. Poética e visualidade. São Paulo: Editora da Unicamp, 1991.

PAZ, Octavio. Marcel Duchamp ou o castelo da pureza. São Paulo: Perspectiva, 1990.

PERLOFF, Marjorie. The poetics of indeterminacy: Rimbaud to Cage. Evanston: Northwestern University Press, 1993.

PERRONE-MOISÉS, Leyla. Texto, crítica, escritura. São Paulo: Ática, 1993.

PONENTE, Nel10. Klee. Genève: Albert Skira, 1960 .

ROSENTHAL, Mark. Anselm Kiefer. Chicago, Philadelphia: The Art Institute of Chicago and The Philadelphia Museum of Art, 1987.

TERENZIO, Stephanie. The prints of Robert Motherwell. New York: Hudson Hills Press, 1991.

ZANINI, Walter. História geral da arte no Brasil. São Paulo: Instituto Walter Moreira Salles e Fundação Djalma Guimarães, 1983. 